\title{
Student Presentation Based Effective Teaching (SPET) Approach: A Multiple Instructors Perspective
}

\author{
${ }^{1 *}$ Dr. Morris Thomas, ${ }^{2}$ Dr. Pawan Tyagi, ${ }^{3}$ Dr. Carl S. Moore \\ ${ }^{4}$ Dr. Pamela Hampton-Garland \\ ${ }^{1 *}$ Director, Learning Resources Division, Center for the Advancement of Learning 4200 Connecticut Ave. N.W. \\ Building 41/Room 201F Washington, DC 20008, United States \\ morris.thomas@udc.edu \\ 2* Assistant Professor, Mechanical Engineering 4200 Connecticut Ave. N.W. Building 42/Room 213E \\ Washington, DC 20008, United States. \\ ptyagi@udc.edu
}

Abstract: Effective teaching approaches require a lot of time investment in student activities during the class period and lead to less coverage of the syllabus. Incomplete course coverage and the amount of time required by an instructor for designing active teaching strategies are cited as the common hindrance in adopting student active teaching. To address these widely recognized inhibiting factors the authors implemented a new active learning approach. This approach is based on the students' presentation and hence termed as the Student Presentation Based-effective Teaching (SPET). The SPET approach was designed to address the key components of effective teaching. However, to understand the efficacy of SPET for different instructors it was implemented into five courses. This study presented the responses and insights garnered from the different instructors who participated in the study. Employing the case study methodology participating instructors reflected their views about the advantages and challenges associated with the adaptation of SPET as compared to lecture based designed courses. The results provided implication for instructional strategies that instructors can consider when integrating active-learning approaches in their courses.

Keywords: Learning Objectives, Bloom's Taxonomy, Active-Learning

\section{INTRODUCTION}

A teaching approach that engages students in various activities during instruction and discussion is more effective than traditional lecture based teaching (Hake, 1998). Effective teaching approaches require a lot of time investment in learner activities during the class period and lead to less coverage of the syllabi.

Incomplete course coverage and the amount of time required by an instructor for designing active teaching \& learning strategies are cited as the common hindrance in adopting student active teaching (Felder \& Brent, 2009). To address these widely recognized inhibiting factors the authors implemented a new active Learning approach. This approach is based on the students' presentation and hence termed as the Student Presentation-based Effective Teaching (SPET). Active learning involves the learners in conducting activitiesto promote critical thinking about the learning objectives and content in general. Felder \& Brent (2009) illustrated active learning as "anything course-related that all students in a class session are called upon to do other than simply watching, listening and taking notes". There are several strong reasons to advocate the selection of active learning based classroom teaching. An active learning approach can encompass both isolated and highly structured activities to motivate students to take charge of their deep learning (Prince, 2004). Active learning can be applied to both small (Prince, 2004) and large (Crouch \& Mazur, 2001) classes; active learning was found to produce higher and long lasting student learning as compared to the traditional lecture format based 


\section{Student Presentation Based Effective Teaching (SPET) Approach: A Multiple Instructors Perspective}

teaching (Thacker, 1994). During active learning, students receive frequent and immediate feedback about the depth and accuracy of the focused material (Hufnagel, 2011). An active learning approach is very effective in addressing students' stereotypes and learning style preferences (Bain, 2012); A lecture based instruction method may give insignificant consideration to these crucial factors in the student learning (Bain, 2004). Active learning can be very effective in creating personal connections between students and the course material, which strongly increases the student's motivation to learn proactively (Bain, 2004). In addition to the course content, active learning develops life skills like improving subject mastery with others feedback, collaboration, and brainstorming to reach the most rational answers. An active learning approach also promotes a sense of community in the classroom by augmenting, learner-content,learner-learner and instructor-learner interaction. However, efficacy of a student learning approach will depend on how many elements of learning it encompass (Ambrose, Bridges, Dipietro, Lovett and Norman, 2010). However, effective teaching may be a quite a time consuming endeavor. Faculty who are venturing into employing active-learning instructional approaches may be daunted by the time and effort needed to do so. The recently developed Student Presentation-based Effective Teaching approach (SPET) is presented as a solution to make active-learning instruction more accessible for faculty. The SPET approach can be likened to the flipped classroom approach combined with features of the peer interaction approach. Students are given topics for a class 1-2 two weeks before to understand by self-reading and prepare a coherent presentation for 10-15 min duration. The students subsequently present these presentations, during a designated class. During and after the presentations instructor and peers provide feedback or ask questions to increase the impact and value. Initially, SPET was applied in small class environments where the instructor found it very rewarding in terms of student learning and course coverage without making significant efforts. However, we were unsure about the SPET in the context of large lecture type classes. To understand the suitability of SPETs adaptability in different courses a number of faculty members at a public urban land-grant institution incorporated SPET methodology in their courses. This study reports observations and findings of the SPET adaptation from different instructors in a variety of courses.

\section{LITERATURE REVIEW}

The focus of this study was on the implementation of a teaching approach (SPET) that encourages effective teaching by leveraging students as instructional tools to provide instruction to their peers. SPET builds on a sturdy foundation of literature to inform this approach. Thus, a brief overview of the pertinent literature relevant to this was included in this section. It contains literature from the areas of learning-centered teaching, student learning theory, and best practices. These areas of literature all have a direct impact on SPET.

\section{LEARNING-CENTERED TEACHING}

It is important to note that though SPET is a strategy for effective teaching, it is informed by philosophical underpinnings. The first of which is constructivism. The constructivist model views educators as educational guardians and role models. From the constructivist perspective, a teacher is a facilitator of learning instead of only serving as a knowledge giver (Lebow, 1993; Alters \& Nelson, 1992; Arends, 2014). Even constructivism builds on the works of educational pioneers such as Paulo Freire. Freire (1996) expresses his definition of pedagogy as what activist teachers do, which is "problem-posing education." Problem posing is to be contrasted with "banking education," which teaches students merely to be passively observant of reality.

This study shares the Freirian outlook and its emphasis on pedagogy as creative transformation. It challenges the "banking" approach to teaching by sharing the instructional process with the learners. This "sharing" of the process of teaching and learning Freire speaks of in contemporary terms is known as learning/student-centered teaching. Such an approach calls for educators to focus on what they want students to learn, versus letting what they want to 'teach' approach (Huba\& Freed, 200; Weimer, 2002). SPET is an approach that is learning-centered at its core. By focusing on student learning, the learners are employed to assist in the teaching. 
Student Presentation Based Effective Teaching (SPET) Approach: A Multiple Instructors Perspective

STUDENT LEARNing THEORIES

Beyond serving to be a learning centered strategy, SPET aims to include learners from a range of learning orientations. Though there has been a wealth of research into learning theory, the most notable and influential perhaps have been Howard Gardner's (1991) Multiple Intelligences; and Flemming\& Mills (1992) Visual Auditory and Kinesthetic (VARK) learning theories.

\section{Multiple InTElligences}

Gardner's works (1991) was one of the first to challenge traditionally-held concepts of teaching and what is "smart" by asserting that people are intelligent in a variety of ways. Gardner's work argues against ways of assessing what students know (intelligence) solely through writing and paper tests, for he asserts that learners have a combination of several intelligences that inform how they learn: linguistic, logical-mathematical, spatial, bodily-kinesthetic, interpersonal, intrapersonal, and musical. Though some have debated Gardner's theories, questioning the validity of the specific Multiple Intelligences he promoted, the conversation about the learning strengths students bring to classrooms cannot be contested. The very fact that Gardner's work and other learning theories have been vigorously debated may contribute to some educators not fully accepting the value of these "theories" - and what learners bring with them to the classroom. The SPET approach, while not, promoting a specific theory recognizes student strengths and leverages it for effective teaching. Next, we will discuss VARK Learning Styles.

\section{Vark Learning Styles (Preferences)}

Currently, one of the most widely accepted concepts of learning theory is Flemming and Mills' (1992) sensory based learning typology. The typology extends Felder \& Silverman's (1988) Index of Learning Styles (ILS) theory and highlights Visual, Auditory, Read/Write and Kinesthetic (VARK) learning styles (Flemming\& Mills, 1992). Flemming\& Mills suggest that learners have a combination of visual, auditory, read/write and kinesthetic learning styles that all influence the way they learn. The theory promotes that Visual learners learn best through diagrams and seeing; Auditory learners through hearing information; Read Write Learners benefit most from writing and/or reading; and kinesthetic learners learn most through the use of touch and movement.

More progressive references to the VARK theory have replaced learning "styles" with learning "preferences", to avoid typecasting learners as having fixed learning orientations. Educators now understand that learners may have VARK learning preferences that differ depending on context/content. Though learning theory has built on and diverged from the aforementioned areas of student learning, learning theorists agree that people learn through rehearsal, through the connection of new information to what they already know, and through motivation (Bransford, Brown, \& Cocking, 1999; Svinicki\&mckeachie, 2006). SPET draws on these understandings to promote effective teaching.

\section{Best Practices}

\section{Active Learning}

One of the best practices in higher education to encourage effective teaching is the promotion of active learning (Alters \& Nelson, 2002). In essence, it can be described as a process where students are engaged with content and activities by the instructor to promote learning. Bonwell\&Eison (1991) were the first to share a range of strategies that classify as active learning. It highlighted the difference between the unidirectional direct instruction approaches (i.e. Lecture, reading text etc), to methods that require the learners move beyond passively absorbing information and doing something with it. The strength of active learning is that it puts more of the accountability for learning on the learners. Similarly SPET encourages learning accountability by involving students in the learning process to educate their peers. 


\section{Student Presentation Based Effective Teaching (SPET) Approach: A Multiple Instructors Perspective}

\section{Flipped Classrooms}

In recent years the flipped classroom strategy has become a popular approach educators have leveraged to improve effectiveness. It builds on the learner accountability promoted by active learning and allows students to do outside of class what they would normally do inside the classroom and vice versa (Berrett, 2012). Flipped models usually use class time to engage students in activities beyond passive receipt of information. The approach provides the opportunity for instructors to better encourage student learning beyond the remembering and understanding levels of Bloom's Taxonomy (Anderson, Krathwohl, and Bloom, 2001). SPET builds on this concept of having students use time outside of class to build their knowledge about the course content and learn it to the degree that they will teach their peers. SPET promotes the highest level of bloom (creation), but having students use what they have learned for peer instruction.

The focus of this study is on the implementation of a teaching approach (SPET) that encourages effective teaching by leveraging students as instructional tools to provide instruction to their peers. SPET builds on a sturdy foundation of literature to inform this approach. Thus, a brief overview of the pertinent literature relevant to this is included in this section. It contains literature from the areas of learning-centered teaching, student learning theory, and best practices. These areas of literature all have a direct impact on SPET.

It is clear that within the SPET approach are the elements of a range of effective teaching theory and practice. The approach operationalizes the advancements in teaching to provide a practical strategy for instruction. Next, we will discuss how SPET was applied in the teaching practices of five faculty and dig deeper in to understanding the tactic.

\section{RESUlTS AND DiscusSions}

\section{Methods, Techniques, or Modes of Inquiry}

The study is qualitative with two foci: (1) direct observation, analysis, and evaluation of the teaching practices of five faculties, (2) assessment, via interviews, of faculty participants using SPET. This study is designed to collect evidence on how faculties employ SPET into their courses. Also, included are perceptions of the students taught using this method. It was imperative that a specified criteria be identified and employed for consistency (Marshall \&Rossman, 2010; Mayring, 2000). The data collection consisted of interviews conducted with the participating faculties. An interview protocol was developed and employed with each participating faculty participant (the interview protocol is included in the data analysis section below).

\section{Data Sources, Evidence, Objects, or Materials}

The case study methodology was employed to analyze the data for this study. Creswell (2003) dates the case study methodology to the work of Malinowski, an anthropologist who studied the Trobriand Islands. This method of collecting data has been used in many disciplines, such as anthropology, sociology, psychology, political science, social work, management, and education (Creswell, 2003; Merriam, 1988; Yin, 1994). Creswell (2003) defines the case study methodology as a detailed collection of data from multiple sources of information through extensive exploration in a bounded system. According to Merriam (1998), a case study is distinct from other methods due to its involving one site during the research process. A case study approach can be combined with other research methodologies such as grounded theory and ethnography (Merriam, 1998).

Yin (1994) recommends using a case study when a "How" or "Why" question needs to be addressed. Yin (1994) also recommends using the case study method when the focus of inquiry is a contemporary phenomenon. Furthermore, case studies are appropriate when the researcher lacks experimental control over events (Yin, 1994). A case study is a methodology similar in many ways to an ethnographic case study. In this particular study the case study method was chosen instead of ethnography because of the limited time constraints. A case study takes place over a sustained period of time, whereas an ethnography takes place over an extended time frame (Creswell, 2003). Case studies involve the collection of data related to an individual or small group 


\section{Student Presentation Based Effective Teaching (SPET) Approach: A Multiple Instructors Perspective}

through observation, interviews, and the collection of documentary evidence. In this study the data was collected by interviews. Moreover, case studies offer a method of learning about a complex instance through extensive description and contextual analysis (Yin, 1994). The outcome of such case studies expresses why the instance occurred as it did, and what one might usefully explore in similar situations (Yin, 1994).

The primary units of analysis for this study involved the participating faculty. The interviews with the participating faculty provided the data source used to examine SPET. The interviews provided a great deal of feedback as it pertained to SPET. On average it took an hour to conduct the interviews. The principle researchers developed the interview protocol for target faculty. During the interviews, specific questions were asked about SPET as well as what the participating faculty observed as a result of implementing SPET. All interviews were audio recorded and transcribed using Dragon Dictation transcription software.

In order to identify the many documents and interactions, as each piece of data (e.g., interview) was obtained, the researcher's assigned it a number (e.g. 1, 2, 3...) and a code to identify the type of data and or from where the data came (e.g., F-1, F-2, etc, SPET...).

Once the information was gathered and separated into units, the data were sorted by research questions (Miles \&Huberman, 1994; Krippendorff, 2004). After the data generation and initial data unitization processes were completed, the researcher's reviewed the data and categories (Krippendorff, 2004). Then, the researcher's grouped the data discussed at greater length and arranged the constructs in emergent categories. This reconstructive process is the foundation for establishing the credibility of the data analysis (Creswell, 2005).

On a scale of 1-5 please indicate

The highlighted scores provided reflect the average scores for the faculty participants' responses to the following questions.

The degree of ease of adopting the Student Presentation-Based Effective Teaching (SPET).

\begin{tabular}{|l|l|l|l|l|}
\hline 1 & 2 & 3 & 4.2 & 5 \\
\hline
\end{tabular}

The degree of satisfaction with SPET with regards to student learning

\begin{tabular}{|l|l|l|l|l|}
\hline 1 & 2 & 3 & $\mathbf{4 . 6}$ & 5 \\
\hline
\end{tabular}

The degree of willingness to adopt SPET in future courses

\begin{tabular}{|c|c|c|c|c|}
\hline 1 & 2 & 3 & 4.6 & 5 \\
\hline
\end{tabular}

What is the name of your course \& course description?

The name of the courses taught by the participating faculty in this study included:

Photovoltaic \& Solar thermal- a senior level mechanical engineering course. Students have already completed basic engineering course and come to this course to learn advanced level technologies.

Wireless Communications- a Graduate course on wireless communication, channel modeling, quality of service, diversity methods, equalization in wireless communication methods.

Adult Development, Learning and Motivation- a graduate course on how adults learn for adult educators, their development from the early 20s through the life-span of the adult and what motivates the adult to learn.

Senior Capstone Design for Mechanical Engineering- Students systematically learn fundamentals of mechanical design and the practice through different projects and present their results.

Engineering Mechanics I- Undergraduate course: they're learning about applying Newton's $2^{\mathrm{ND}}$ law for non-accelerating bodies in equilibrium. 
Student Presentation Based Effective Teaching (SPET) Approach: A Multiple Instructors Perspective

What is the size of your class?

The sizes of the five classes ranged from 1-37.

\begin{tabular}{|c|c|}
\hline FACULTY & CLASS SizE \\
\hline F-1 & 12 \\
\hline F-2 & 1 \\
\hline F-3 & 6 \\
\hline F-4 & 9 \\
\hline F-5 & 37 \\
\hline
\end{tabular}

\section{What are the advantages of SPET?}

The faculty participants reported the following concerning the pros as it pertains to SPET, F-1 reported, "It covers detailed discussion on complicated concepts. Reflect student level of understanding up-front during the presentation. This faculty also commented that many students form foreign cultures also have the opportunity to experiment with their communication and presentation skills. F-2 suggested that the SPET allows a course to cover a lot more material. This faculty said, "It put the burden for learning on the student instead of on the instructor, and saved me time, and we have fruitful discussion as of the students having read the material prior to class. So, it was good." F-3 said the best part of SPET is to hear students' voices prior to reviewing the chapter materials. F-4 said, "It more engages students and helps them to self-learn and self-study the project and practice the presentations skills and promotes team-work and prepare them prior to entering real jobs to know how to do independent study and apply previous knowledge. Lastly F-5 said that, "students are more likely to ask questions to other students, so I noticed that. There is more discussion because of that, from the students at the board and the students that are in the audience."

\section{What are the disadvantages of SPET?}

All faculty reported that class size is a con for SPET, F-4 said, "in a large class the use of SPET would be limited, it could be adapted but it cannot entirely be used." Similar to the previous faculty's concern, F-1 said, "time management is an issue; it is challenging to include everybody's presentation in the class duration." Other than time, F-1, F-3 and F-5 reported students having concerns about being prepared to conduct presentations. Sometimes students complain about the pressure of preparing presentation for consecutive classes. Nevertheless, F-2 said, "for the course that I did, I cannot think of any cons, but there might be cons in larger courses or for undergraduate courses, but for this class it worked beautifully."

What are the group sizes of SPET for your course? The SPET group comprises of student presenters for the designated class.

\begin{tabular}{|c|c|}
\hline FACULTY & GROUP SIZES \\
\hline F-1 & 4 PER GROUP \\
\hline F-2 & 1 (ONLY ONE STUDENT IN THE CLASS) \\
\hline F-3 & 1 OR 6 PER GROUP \\
\hline F-4 & 4 GROUPS OF 2 \& 1 GROUP OF 3 \\
\hline F-5 & 2 PER GROUP \\
\hline
\end{tabular}

What levels of Bloom's Taxonomy do you think are being addressed during SPET?

\begin{tabular}{|c|c|}
\hline BLOOM'S TAXONOMY LEVELS & $\begin{array}{c}\text { WHICH LEVELS FACULTY PARTICIPANTS THOUGHT SPET } \\
\text { ADDRESSED }\end{array}$ \\
\hline CREATING & F-4, F-5 \\
\hline EVALUATING & F-1, F-4, F-5 \\
\hline
\end{tabular}

American Research Journal of Humanities and Social Sciences 
Student Presentation Based Effective Teaching (SPET) Approach: A Multiple Instructors Perspective

\begin{tabular}{|c|c|}
\hline ANALYZING & F-1, F-3, F-4, F-5 \\
\hline APPLYING & F-1, F-3, F-4. F-5 \\
\hline UNDERSTANDING & F-1, F-3, F-4, F-5 \\
\hline REMEMBERING & F-1, F-3. F-4, F-5 \\
\hline
\end{tabular}

F-2 opted not to answer this question because this faculty did not believe in Bloom's taxonomy. It is also important to note that while F-5 thinks SPET can address all levels of Bloom's Taxonomy, this faculty said, "Because it' a sophomore level course on the lowest three level of Bloom's taxonomy are being addressed but in a higher level course the other levels would be addressed and even the lower levels the learners have some difficulties. In this course we are focusing on the bottom three levels and building the base."

\section{Do you find that the students follow the rubric?}

All the participating faculties reported that their students followed the rubric. F-3 reported that, "I think know they follow the rubric to a point but I do believe they exceed the expectations of the rubric..." while F-4 reported that, "you just have to tell them...In the beginning I showed them an example of how I prepare my presentations, after the first round of presentations and having being evaluated they are doing better the second time.

\section{What learning styles/preferences are accommodated by SPET?}

The faculty participants reported that the following learning styles/preferences are accommodated by SPET

- Visual

- Auditory

$\circ$ Reading/Writing

○ Kinesthetic

F-2 said, "I think I found it very useful that they read the materials ahead of time, they have a better understanding of the materials, rather than me lecturing and they come and make presentation and they ask me very deep and detailed questions about something they haven't understood apart from the fact that the student that I am working with is very good anyway." F-3 explained that SPET addressed most of the aforementioned learning styles, due to the various components required to conduct the SPET process. F-3 reported that, "I provided examples of how to present the content in their groups and it included reading, writing, video, and presenting."

\section{Were you prepared to implement SPET?}

Four of the five faculty participants reported that they were prepared to implement SPET. F-4 added that the professional development provided by the institutions Center for Teaching \& Learning helped in preparing the implement SPET. However, F-5 reported, "Not in the context of how it was proposed because of the level of the course. But I still wanted to use it (SPET) because the students are getting to present the information and are able to internalize it. In a lower level course students might get lost if they are presenting on an entire chapter they are more likely to better implement and use SPET due to having a foundational knowledge of the content.

\section{What do you think you can do better in implementing SPET in future courses?}

F-1 said, "Depending upon enrollment, I would prefer to give presentation assignment to only 2 to 3 students per class. The remaining students will be presenting as their turns come.

I think if it a larger course you have to be very organized and keep reminding students of their responsibilities and what can make SPET really not work is that students come to class and not have done their part, because the model is that they do the work prior to class and if they don't do that it goes back to the traditional way and if the learners are not prepared and you are not prepared to lecture it is not good." F-2 had no suggestions for better implementation of SPET, this faculty was completely satisfied with the SPET implementation. F-3 


\section{Student Presentation Based Effective Teaching (SPET) Approach: A Multiple Instructors Perspective}

thought that better preparing the students to conduct the presentations would be useful in future courses. F-3 said, "I think I can develop some smaller modules for students to present, to adapt and use for smaller class size. I could give more handouts in the beginning of class on how to prepare for the class, so the students can have a better idea of how to best use this opportunity to learn. I would say if students had this opportunity previously they would have an idea, but if this was their first time they need more instructions and preparation to be able to complete the presentations."

\section{In what ways did SPET support the course's learning objectives?}

The faculty reported that SPET supported the students' ability to take leadership in becoming expert in certain areas and improved their communication skills. F-1 said, "students learn to respect others ideas and thoughts while doing discussion about their presentation." F-2 said, "It enhanced the students' understanding of the subject and allows for more materials to be covered because so much work is being done by the student outside of the classroom." F-3 reported that SPET perfectly aligned with the course objectives, "because I can use the four questions to align perfectly with the course objectives. "It is a great way to assess students' learning, the other good thing is that because they have to submit their presentations to me prior to presenting them to the class thus providing a pre-post assessment opportunity. Additionally, it allows me as the professor to know what information will need clarity and where students have mastery." F-4 said, "We used the ABET (Accreditation Board for Engineering and Technology) learning objectives in our classes. For this class in particular, we try to let students be able to apply and implement their previous knowledge from their previous 3 years of study, so using this practice it helped the students have more opportunities to apply their knowledge and solve real problems and be more prepared by the time they graduate. So basically this class is not teaching new knowledge but it is allowing them to put all of their previous knowledge together and by using this method they are able to apply and use their prior knowledge." F-5, also used ABET and said, "SPET allows for more communication activities (which is an objective for ABET) and these communication activities should be implemented in the courses so when students are conducting presentations, there is more communication and at the same time students are learning from this experience."

\section{In what ways did SPET increase learning outcomes?}

The faculty reported that SPET allowed them to cover more course material in an active learning framework. F-1 said, "Student active learning approaches generally tend to cover less material but this is not the case with SPET. Based on my observation, student digest a concept from multiple standpoints. SPET allowed the students to see concepts from multiple views and gain a deeper understanding." F-3 said, "SPET increased learning outcomes because it allowed students to actually engage in the materials very thoroughly prior to hearing the instructor's perspective. It is a very learner-centered approach instead of teacher-centered and allowed them to develop their own perspective prior to hearing the instructor's perspective. This way they do not try to only accommodate the professor's perspective but develop their own views." F-4 said, "I think at first because they have to, it kind of forced them to read and understand their material beforehand it kind of helps them to understand the course content better or be more prepared before they come to class. And I think it (SPET) also provided them more opportunities to do more technical writing and presentation and to learn these crucial skills which is kind of lacking in engineering students, they don't get enough training in that aspect. While F-5 said, "I am not sure yet, but I will know at the end of the course once assessments are complete. I will need to compare assessments results with previous years. I will likely ask a few more questions to assess whether they thought this experience helped them to learn the content better."

\section{IMPLICATION FOR PRACTICE}

It is apparent that SPET has received favorable response from most of the properties. This teaching approach enabled groups of students to prepare presentations on the critical elements of the chapter or section as assigned by the instructors to measure their comprehension of the material. The student presentations have multiple objectives. The first objective is to demonstrate the student presenter understanding in a manner that other 


\section{Student Presentation Based Effective Teaching (SPET) Approach: A Multiple Instructors Perspective}

students learn the concepts. The second objective is that when multiple presenters do presentations on similar topics the repeating of the concepts by different students from multiple angles help reinforce the understanding of the concepts. However, it is very crucial that instructors prepare a rubric to discipline student presentations. How well SPET can be productive for a class will be based on the instructors' ability and willingness to make use of presentations on the same topic in a class.

It was observed that if three to four presentations are providing the same information then students in the class start getting bored and complain about redundancy. However, if the first one or two presentations are used to prepare the background knowledge for the whole class and the next two presentations are utilized to perform "what if" analysis about the targeted concepts. Students appeared to remain engaged in the process and learned at a rate that exceeded traditional classroom delivery methods. It is essential that faculty also use this opportunity to provide formative feedback to students regarding their communication skills. The SPET approach is designed to encompass research based effective teaching elements. Different instructors can have likings for different elements of effective teaching and they will be able to enhance their preferred elements by developing complimentary activities and rubrics.

\section{Conclusion And Future Recommendations}

This study provided the insights from different faculty who experimented with the SPET approach. According to the participants feedback most of them find SPET useful as indicated in the response of several questions asked during this study. However, it is very clear that SPET works best for the smaller sized class. However, for most of the classes with more than five student enrollment it is understood that not all the students will be able to present every class, and hence some complementary class activities must be administered for the non-presenting students. Different instructors can decide various types of activities for the non-presenting students to motivate their preparation for the subject matter, along with the presenting students. It may be very interesting to study the impact activities for the non-presenters in different classes taught by the different faculty members. In future studies it is recommended that faculty members participating in the study use a common rubric to evaluate the student presentations and also comment on student performance in their classes while providing their feedback.

In summary, we have discussed the scope of the Student Presentation-based Effective Teaching (SPET) approach from the stand points of multiple faculty members teaching a variety of courses. The SPET approach was designed to address the limitations of common active teaching approaches for the technically advanced courses where students are expected to apply advanced math and science concepts. However, in this study it was adapted to a variety of non-math courses and it is determined that its success is largely dependent upon the number of students in the course and the actual method used to implement the approach.

\section{REFERENCES}

Alters, B.J., \& Nelson, C.E.(2002). Perspective: Teaching evolution in higher education. Evolution, 56(10), 1891-1901.

Anderson, L. W., Krathwohl, D. R., \& Bloom, B. S. (2001). A taxonomy for learning, teaching, and assessing: A revision of Bloom's taxonomy of educational objectives. Allyn \& Bacon.

Ambrose, S. A. (2010). How learning works: Seven research-based principles for smart teaching. San Francisco, CA: Jossey-Bass.

Bain, K. (2004). What the best college teachers do. The American Biology Teacher, 66(8), 578-579.doi: $10.2307 / 4451746$

Bain, K. (2004). What the best college teachers do. Cambridge, MA: Harvard University Press.

Bain, K. (2012). What the best college students do. doi:10.4159/harvard.9780674067479 
Student Presentation Based Effective Teaching (SPET) Approach: A Multiple Instructors Perspective

Berrett, D. (2012). How 'flipping'the classroom can improve the traditional lecture. The chronicle of higher education, 12, 1-14.

Creswell, J. W. (2003). Qualitative inquiry and research design: Choosing among five traditions. Thousand Oaks, Calif. [u.a.: Sage.

Creswell, J. W. (2005). Educational research: Planning, conducting, and evaluating quantitative and qualitative research. Upper Saddle River, NJ: Merrill.

Crouch, C. H., \& Mazur, E. (2001). Peer instruction: Ten years of experience and results. American Journal of Physics, 69(9), 970. doi:10.1119/1.1374249 Fleming, N., \& Mills, C. (2001). VARK: A guide to learning styles.

Retrieved November, 30, 2004.

Hake, R. R. (1998). Interactive-engagement versus traditional methods: A six-thousand-student survey of mechanics test data for introductory physics courses. American Journal of Physics, 66(1), 64. doi:10.1119/1.18809

Huba, M. E., \& Freed, J. E. (2000). Learner centered assessment on college campuses: Shifting the focus from teaching to learning. Community College Journal of Research and Practice, 24(9), 759-766.

Hufnagel, B. (2011). Innovative strategies for empowering your students to become active, responsible learners. In Earth and space science: Making connections in education and public outreach (p. 405). Retrieved from http://adsabs.harvard.edu/abs/2011ASPC..443..405H

Krippendorff, K. (2004). Content analysis: An introduction to its methodology.

Lebow, D. (1993). Constructivist values for instructional systems design: Five principles toward a new mindset. Educational technology research and development, 41(3), 4-16.

Marshall, C., \&Rossman, G. B. (1995). Designing qualitative research. Thousand Oaks, CA: Sage Publications.

Prince, M. (2004). Does Active Learning Work? A Review of the Research. Journal of Engineering Education, 93(3), 223-231. doi:10.1002/j.2168-9830.2004.tb00809.x

Thacker, B. (1994). Comparing problem solving performance of physics students in inquiry-based and traditional introductory physics courses. American Journal of Physics, 62(7), 627. doi:10.1119/1.17480

Weimer, M. (2002). Learner-centered teaching: Five key changes to practice. John Wiley \& Sons.

\section{Contribution by authors}

Dr. Morris Thomas provided administrative oversight for the study in addition to writing the manuscript , collecting \& analyzing the data for this study. Dr. Pawan Tyagi invented the SPET approach and provided guidelines for adopting this approach in different courses and also contributed in manuscript preparation. Dr. Carl S. Moore helped in shaping the idea for this project and contributed in drafting the manuscript. Dr. Pamela Hampton-Garland participated in the SPET study and also contributed in drafting the manuscript."

Citation: Dr. Morris Thomas, Dr. Pawan Tyagi, Dr. Carl S. Moore, Dr. Pamela Hampton-Garland "Student Presentation Based Effective Teaching (SPET) Approach: A Multiple Instructors Perspective." American Research Journal Of Humanities And Social Sciences, vol 3, no. 1, 2017, pp. 1-10.

Copyright (c) 2017 Dr. Morris Thomas, Dr. Pawan Tyagi, Dr. Carl S. Moore, Dr. Pamela Hampton-Garland This is an open access article distributed under the Creative Commons Attribution License, which permits unrestricted use, distribution, and reproduction in any medium, provided the original work is properly cited. 